of International Education (1951-54). These experiences with international affairs shifted Du Bois' attention away from psychocultural research in isolated societies toward broad questions of social, political, and cultural change in modern nationstates. It was during this period that she published Social Forces in Southeast Asia (1949).

Du Bois returned to academe in 1954 as Zemurray Professor of Anthropology at Harvard University, where she remained-as the only tenured woman in the department-until her retirement in 1969. The culmination of her research career was the "Harvard-Bhubaneswar Project," an ambitious study of sociocultural change in India, the most complex society she had yet encountered. From 1961-72, Du Bois directed a long-term, multidisciplinary study of a community in India undergoing change from a small, medieval temple town to a modern city of administration.

The Harvard-Bhubaneswar Project exemplified many of Cora Du Bois' personal and intellectual qualities. Conceptually, the project reflected her interest in broad patterns of historical and sociocultural change as well as her recognition that discrete, well-executed studies are required to gain insight into such complex processes. (She always remained suspicious of facile sociocultural generalizations.) Thus, she devised a collaborative and interdisciplinary program in which she supervised the research of fourteen Indian and American graduate students in an exacting manner, while also serving as a personally and intellectually supportive mentor. She was a superb teacher and adviser, her inclination being to challenge and nurture, never to impose or constrain.

Cora Du Bois will be remembered as one of the pioneers in American anthropology and Asian studies. Space does not permit reciting the numerous honors Du Bois received during her lifetime, but it is fitting to note that her two principal professional organizations awarded her their top honor: She was elected President of the American Anthropological Association (1968-69) and of the Association for Asian Studies (1969-70).

SUSAN SEYMOUR

Pitzer College

\title{
References Cited
}

DU BoIs, CorA. 1944. The People of Alor, with analysis by A. Kardiner and Emil Oberholzer. Minneapolis: University of Minnesota Press.

— 1980. "Some Anthropological Hindsights." Annual Review of Anthropology $9: 1-15$.

\section{Erratum}

The affiliation of Professor George Rosen, the author of the obituary of Sukhamoy Chakravarty (JAS 50.2:482), is the University of Illinois at Chicago. 